\title{
Intentional Head Injury: Survivor Victim's Profile, Gender Differences and Role of Alcohol Use at Manipal Teaching Hospital, Pokhara, Nepal
}

\author{
Atreya $A,{ }^{1^{*}}$ Kanchan $T^{2}$ Karmacharya $B G^{3}$
}

\section{Affiliation}

1. Lecturer, Department of Forensic Medicine, Nepal Medical College and Teaching Hospital, Kathmandu, Nepal

2. Associate Professor, Department of Forensic Medicine \& Toxicology, All India Institute of Medical Sciences, Jodhpur, India

3. Unit Chief, Neurosurgery Unit, Manipal Teaching Hospital, Pokhara, Nepal

\section{ARTICLE INFO}

Article History

Received : 6March, 2017

Accepted : 6 April, 2017

Published : 30 April 2017

(c) Authors retain copyright and grant the journal right of first publication with the work simultaneously licensed under Creative Commons Attribution License CC - BY 4.0 that allows others to share the work with an acknowledgment of the work's authorship and initial publication in this journal.

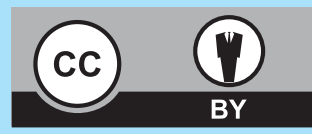

ORA 15

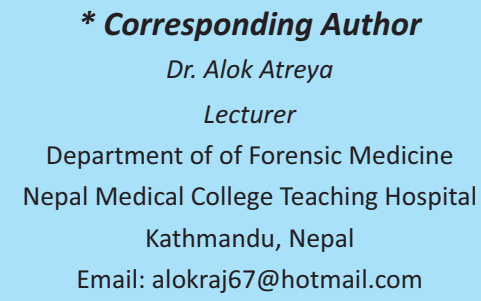

\section{Citation}

Atreya A, Kanchan T, Karmacharya BG. Intentional Head Injury: Survivor Victim's Profile, Gender Differences and Role of Alcohol Use at Manipal Teaching Hospital, Pokhara, Nepal. BJHS 2017; 2(1)2: 102-105.

\section{ABSTRACT}

\section{Introduction}

Head is a vulnerable area in human body and also a favourable site for assaults which is easily accessible by assailant's raised arms.

\section{Objective}

The objective of this study was to evaluate the sociodemographic spectrum, severity, radiological findings and outcome of victims assaulted to the head. Furthermore, the study aims to correlate such findings to the role of alcohol use in Nepalese context.

\section{Methodology}

This longitudinal prospective study includes victims of traumatic head injury as a result of physical assault who were admitted in the Neurosurgery Unit of Manipal Teaching Hospital Pokhara, Nepal from $1^{\text {st }}$ January to $31^{\text {st }}$ December 2015.

\section{Results}

Intentional head injury accounted to $17.40 \%$ of all head injury cases admitted during the study period. Among them 48 (76.19\%) were males and 15 (23.81\%) were females. The minimum age of the patient was 15 years and maximum was 84 years with a mean age of $33.89 \pm 14.67$ years. Most of the victims of physical assault belonged to the age group of 21 to 30 years. Blunt object was the most commonly used for assault. Loss of consciousness was associated only with $49.21 \%$ of cases and $14.29 \%$ cases had bleeding from ear and/or nose. More than $75 \%$ of the cases had significant radiological finding in the form of fracture and/or intracranial lesion. Majority of the victims during the study were treated conservatively and were discharged with advice. Alcohol use was involved in $36.51 \%$ cases of intentional head injuries.

\section{Conclusion}

Intentional injuries under the influence of alcohol use are totally preventable public health concerns. It can be ascertained that reducing availability and improving the environment in which alcohol is sold and consumed can result in a dramatic reduction in violent crimes.

\section{KEYWORDS}

Alcohol, head injury, physical assault 


\section{INTRODUCTION}

Any external injury to face, scalp and calvarium in the form of abrasion, contusion, laceration or fracture is non-specifically designated as head injury. ${ }^{1}$ Traumatic brain injury (TBI) is alteration in brain function as a consequence of penetrating or blunt trauma to head. Head injury can occur without associated TBI and vice versa. Assaults are intentional overt behaviour directed towards another person to cause harm. Intentional head injuries are assaults to the head either to kill or incapacitate a person. Intentional injuries in the form of interpersonal violence range from minor assaults to homicides. These behaviours can be impulsive or premeditated. There are various studies conducted in Nepalese setting on the traumatic injuries, yet no study is found in particular that has in-depth assessment of intentional injuries confined to head. ${ }^{2-6}$ The objective of this study was to evaluate the sociodemographic spectrum, severity, radiological findings and outcome of victims assaulted to the head. Furthermore, the study aims to correlate such findings to the role of alcohol use in Nepalese context.

\section{METHODOLOGY}

With the approval of ethics committee of Manipal Teaching Hospital longitudinal study was carried out. Victims of traumatic head injury as a result of physical assault who were admitted in the Neurosurgery Unit of Manipal Teaching Hospital from $1^{\text {st }}$ January 2015 to $31^{\text {st }}$ December 2015 were included in the study. This study did not include cases of head injury due to physical assault who were brought dead i.e. died on the spot or on the way to hospital and discharged from the emergency department after first aid.

The head injury cases were recorded using a proforma which sought the following information: name, gender, age, address, telephone number, date of incident, diagnosis, vitals including Glasgow Coma Score (GCS), radiological findings, treatment offered, and date of discharge. The proforma also included whether the patient was intoxicated at the time of assault or not. This proforma was attached to the patient's file in the Neurosurgery unit and was completed by the in-trainee doctor on duty. When the proforma was not completed by the doctor on duty, the academic researcher collected the necessary data directly from the patient or a family member. The data were entered, and analyzed using SPSS (Statistical Package for Social Sciences) version 21 and presented in appropriate tables.

\section{RESULTS}

During the one year study period 374 patients were treated for head injury out of which 12 patients died (mortality rate $3.2 \%)$. Of the surviving 362 patients, 63 cases $(17.40 \%)$ had intentional head injury of which $48(76.19 \%)$ were males and
15 (23.81\%) were females. The minimum age of the patient was 15 years and maximum was 84 years with a mean age of $33.89 \pm 14.67$ years. Most of the victims of physical assault belonged to the age group of 21 to 30 years comprising of $41.27 \%(n=26)$ of total study population (Table 1). Glasgow Coma Scale (GCS) on arrival to casualty room was computed to be 5 as the lowest score and 15 being maximum with a mean score of $14.35 \pm 1.97$. On external examination, only 9 patients (14.29\%) had bleeding from ear/nose /throat while 54 patients ( $85.71 \%$ ) had no such bleeding. History suggestive of post traumatic seizure was present only in 2 cases. Headache was the presenting symptom as complained by the patient in 18 cases. The duration of loss of consciousness based upon the history of the patient and/or their caregivers is shown in (Table 2). In 15 cases (24.2\%) there was no visible external injury and the computerized tomographic (CT) scan also did not reveal any intracranial lesion. The pattern of injuries sustained by the victims is shown in the (Table 3). The weapon of offence used by the assailant was blunt object in 44 cases $(69.84 \%)$ and sharp cutting objects in 13 cases (20.63\%). In 6 cases (9.52\%) the offending weapon was not identified (Table 4). Blunt objects included stone and bricks, metal bar, wooden log and sticks, furniture, garden hoes, fists and kicks and intact beer/ whiskey bottles. Khukuri, sickle, knives and axe were the popular sharp weapons in the study. Out of 47 males, 16 were (25.4\%) were intoxicated during assault whereas none of the females in the study had consumed alcohol at the time of assault. History suggested that 7 females were beaten up by their husband or other family members under the influence of alcohol. Alcohol use was involved in $36.51 \%(n=23)$ cases of intentional head injuries. The treatment modality was surgical in 14 cases, conservative in 41 cases whereas 8 cases were admitted for observation (Table 5). The minimal duration of hospital stay was 2 days and maximum of 120 days with a mean of $11.86 \pm 19.84$ days. In the present study 58 patients (92.1\%) were discharged with advice and 2 patients (3.1\%) were discharged on request of patient's care givers whereas 3 cases $(4.8 \%)$ discontinued treatment and left against medical advice (LAMA).

Table 1: Overview of patient demographics $(n=63)$

\begin{tabular}{|lll|}
\hline Age Group & \multicolumn{1}{c}{$\begin{array}{c}\text { Male } \\
n(\%)\end{array}$} & $\begin{array}{c}\text { Female } \\
n(\%)\end{array}$ \\
\hline $11-20$ & $07(11.11 \%)$ & $01(1.59 \%)$ \\
\hline $21-30$ & $18(28.57 \%)$ & $08(12.70 \%)$ \\
\hline $31-40$ & $11(17.46 \%)$ & $01(1.59 \%)$ \\
\hline $41-50$ & $09(14.29 \%)$ & $01(1.59 \%)$ \\
\hline $51-60$ & $02(3.17 \%)$ & $01(1.59 \%)$ \\
\hline$>60$ & $01(1.59 \%)$ & $03(4.76 \%)$ \\
\hline Total & $48(76.19 \%)$ & $15(23.81 \%)$ \\
\hline
\end{tabular}


Table 2: Loss of consciousness and ENT bleeding $(n=63)$

\begin{tabular}{|l|l|l|}
\hline Variable & Category & $\mathbf{n}(\%)$ \\
\hline & None & $32(50.79 \%)$ \\
\hline \multirow{2}{*}{ Loss of } & 10 minutes & $12(19.05 \%)$ \\
\hline consciousness & 30 minutes-1hour & $01(01.59 \%)$ \\
\hline & $>1$ hour $-<12$ hours & $06(09.52 \%)$ \\
\hline ENT bleeding & Ear only & $02(03.17 \%)$ \\
\hline & Nose Only & $02(03.17 \%)$ \\
\hline & Ear and Nose & $06(09.52 \%)$ \\
\hline
\end{tabular}

Table 3: Radiological Findings $(n=63)$

\begin{tabular}{|c|c|c|}
\hline \multicolumn{2}{|l|}{ Findings } & \multirow{2}{*}{$\begin{array}{c}n(\%) \\
15(23.81 \%)\end{array}$} \\
\hline Normal CT Scan of head & & \\
\hline \multirow[t]{6}{*}{ Fractures } & Parietal & $7(11.11 \%)$ \\
\hline & Frontal & 9 (14.29\%) \\
\hline & Temporal & $4(6.35 \%)$ \\
\hline & Occipital & $2(3.17 \%)$ \\
\hline & Nasal & $1(1.59 \%)$ \\
\hline & Maxillary & $3(4.76 \%)$ \\
\hline \multirow[t]{9}{*}{ Intracranial injuries } & Cerebral Contusion & $11(17.46 \%)$ \\
\hline & Cerebral laceration & $2(3.17 \%)$ \\
\hline & Epidural haematoma & $11(17.46 \%)$ \\
\hline & Subdural haematoma & $7(11.11 \%)$ \\
\hline & Subarachnoid & $3(4.76 \%)$ \\
\hline & Intraventricular & $1(1.59 \%)$ \\
\hline & Pneumocephalus & $5(7.94 \%)$ \\
\hline & Haemosinus & $3(4.76 \%)$ \\
\hline & Oedema and brain & $1(1.59 \%)$ \\
\hline
\end{tabular}

Table 4: Weapon of offence $(n=63)$

\begin{tabular}{|l|ll|}
\hline Weapon & Category & $\mathbf{n}(\%)$ \\
\hline Sharp cutting & Axe & $2(3.17 \%)$ \\
& Khukuri & $3(4.76 \%)$ \\
\hline Sickle & $4(6.35 \%)$ \\
\hline Blunt & Knives and other pointed & $4(6.35 \%)$ \\
\hline & Bamboo & $2(3.17 \%)$ \\
\hline & Wooden log/ firewood $5(7.94 \%)$ \\
\hline & Metal bar/rod & $7(11.11 \%)$ \\
\hline & Stick & $3(4.76 \%)$ \\
& Stone/brick & $10(15.89 \%)$ \\
\hline Furniture & $5(7.94 \%)$ \\
& Motorcycle Helmet & $1(1.59 \%)$ \\
\hline Unspecified/Unidentified & $4(6.35 \%)$ \\
\hline
\end{tabular}

Table 5: Treatment modality and discharge $(n=63)$

\begin{tabular}{|c|c|c|}
\hline Variable & Category & n (\%) \\
\hline \multicolumn{2}{|c|}{ Treatment offered Conservative } & $41(65.08 \%)$ \\
\hline & Observation only & $08(12.70 \%)$ \\
\hline & Surgery & $14(22.22 \%)$ \\
\hline \multirow[t]{3}{*}{ Discharge } & On Advice & $58(92.06 \%)$ \\
\hline & On Request & $02(03.17 \%)$ \\
\hline & Left Against Medical Advice & $03(04.76 \%)$ \\
\hline
\end{tabular}

\section{DISCUSSION}

Intentional assault to head comprised of $17.40 \%$ of all head injury cases which is similar to a study conducted in university hospital in eastern Nepal. ${ }^{2}$ The present study observed high number of interpersonal violence during adolescence and young adulthood with a male/female ratio of 3.2. Contrastingly during old age number of females being admitted for intentional assault was higher than males.

It is suggested that females develop internalizing (depressive) symptoms rather than externalizing (angry) symptoms as in males. Lesser number of female victims in intentional assault may be attributed to the fact that violence upon female posses a greater risk for suicide. ${ }^{7}$ Joshi (2009) points out some reasons for under reporting of violence against women to save family prestige and privacy, fear of husband and mother-in-law, love and affection with husband and family members, fear of breaking family relation, fear of social, traditional and socio-cultural values, fear of further beating, physical assault, marginalization, uncertainty of justice, lack of faith in justice and support of other. ${ }^{8}$ Intentional head injuries in females due to intimate partner brutality are likely either not to seek medical care at all or to shun medical care and depart from hospital in advance than scheduled. ${ }^{9}$

Head are the target regions in most assaults as it is easily accessible by assailant's raised arms. Males suffer more serious injuries when compared to females as violence in males usually involves dangerous weapons and objects. ${ }^{10}$

Males in their testosterone years are involved into violence and assault within their peer group (friends or strangers). Physical aggression by males who consumed alcohol usually involve four or more men while incidents and females with no alcohol consumption was with known male most often a family member in domestic setting. ${ }^{11}$ Tendency of substance abuse and alcohol use was higher among assaulted males while none of the females had a history of alcohol consumption prior to the assault. The known risk factor for violence in males include low self-esteem, apathy to personal safety and the inability regulating emotional responses to stress. ${ }^{12}$ 
In Nepal, the liquor law is not strict. Let aside the tea-shops, almost all the grocery shops in the country sale alcoholic beverages. The environment in which alcohol is sold and consumed if changed reducing the access, we could see the dramatic decline in alcohol-associated violence.

Physical assault and violence possess a threat not only to the well-being of individuals but also to the families and communities. There are devastating consequences of violence in the form of psychological and emotional problems which may affect the communication between patients and health professionals. ${ }^{13}$

Patients with intentional head injuries are more likely to be discharged home than rehabilitation when compared to the patients with unintentional head injuries. ${ }^{14}$ They also had higher caregiver burden and less community reintegration. ${ }^{15-16}$

In the present study it was seen that $4.8 \%$ of population left against medical advice and $3.1 \%$ requested for discharge. Studies have suggested that patients with history of alcohol/drug abuse mistrust medical care givers, and also their addictive behaviour - the desire to get more drug and alcohol once discharged is high. ${ }^{17-18}$

\section{REFERENCES}

1. Burns J Jr, Hauser WA. The Epidemiology of Traumatic Brain Injury: A review. Epilepsia 2003;40:2-10.

2. Bajracharya A, Agrawal A, Yam BR, Agrawal CS, Lewis O. Spectrum of surgical trauma and associated head injuries at a university hospital in eastern Nepal. J Neurosci Rural Pract 2010;1:2-8.

3. Shrestha R, Shrestha SK, Kayastha SR, Parajuli N, Dhoju D, Shrestha D. A Comparative Study on Epidemiology, Spectrum and Outcome Analysis of Physical Trauma cases Presenting to Emergency Department of Dhulikhel Hospital, Kathmandu University Hospital and its Outreach Centers in Rural Area. Kathmandu Univ Med J 2013;11:241-6.

4. Joshi SK, Shrestha S. A Study of Injuries and Violence Related Articles in Nepal. J Nepal Med Assoc 2009; 48:209-16.

5. Ghimire A, Nagesh S, Jha N, Niraula SR, Devkota S. An Epidemiological study of injury among urban population. Kathmandu Univ Med J2009;7:402-7.

6. Sharma G, Shrestha PK, Wasti H, Kadel T, Ghimire P, Dhungana S. A review of violent and traumatic deaths in Kathmandu, Nepal. Int J Inj Contr Saf Promot 2006;13:197-9.

7. Conner KR, Cox C, Duberstein PR, Tian L, Nisbet PA, Conwell Y. Violence, alcohol, and completed suicide: a case-control study. Am J Psychiatry 2001; 158:1701-5

8. Joshi SK. Violence against women in Nepal: Role of health care workers. Kathmandu Univ MedJ 2009;7:89-90.

9. Corrigan JD, Wolfe M, Mysiw WJ, Jackson R, Bogner J. Early identification of mild traumatic brain injury in female victims of domestic violence. Am J Obstet Gynecol 2003; 188(5):71-6.
There is a need of wider and more comprehensive awareness programs of these overwhelming consequences of assault from public health perspectives.

\section{CONCLUSION}

The connection between alcohol and intentional injuries signifies a stern public health and safety which is totally preventable. The law and policy makers should recognize how crimes are linked to alcohol consumption and therefore plan and implement alcohol law in the country with top priority. Inadequate attention to alcohol law enforcement as in the current scenario increases alcohol-related violence and its associated human, social, and economic costs. Liquor laws also have a positive impact on alcohol-related traffic accidents. The present study demonstrates the urgency in enforcing alcohol law and innovative strategies for prevention of staggering violence and highlights the need for further research to measure enforcement's impact and optimal design.
10. Goulart DR, Colombo Ldo A, de Moraes M, Asprino L. What is expected from a facial trauma caused by violence? J Oral Maxillofac Res 2014;5(4):e4.

11. Graham K, Wells S. The two worlds of aggression for men and women. Sex Roles 2001; 45:595-22.

12. Ranney $M L$, Whiteside $L$, Walton $M A$, Chermack ST, Zimmerman MA, Cunningham RM. Sex Differences in Characteristics of Adolescents Presenting to the Emergency Department with Acute Assaultrelated Injury. Acad Emerg Med 2011;18:1027-35.

13. Bogner JA, Corrigan JD, Mysiw WJ, Clinchot D, Fugate L. A comparison of substance abuse and violence in the prediction of long-term rehabilitation outcomes after traumatic brain injury. Arch Phys Med Rehabil 2001; 82(5): 571-7.

14. Esselman PC, Dikmen SS, Bell K, Temkin NR. Access to inpatient rehabilitation after violence-related traumatic brain injury. Arch Phys Med Rehabil 2004; 85(9), 1445-9.

15. Gerhart KA, Mellick DC, Weintraub AH. Violence-related traumatic brain injury: A population based study. Journal of Trauma 2003;55:1045-53.

16. Hanks RA, Wood DL, Millis S, Harrison-Felix C, Pierce CA, Rosenthal $M$, et al. Violent traumatic brain injury: Occurrence, patient characteristics, and risk factors from the traumatic brain injury model systems project. Arch Phys Med Rehabil 2003;84(2):249-54.

17. Alfandre DJ. "I'm going home": Discharges against medical advice. Mayo Clinic Proc 2009; 84(3):255-60.

18. Saitz R. Discharges against medical advice: time to address the causes. CMAJ 2003;167(6):647-8. 